Article

\title{
Modeling the Performance of a New Speed Adjustable Compound Supercharging Diesel Engine Working under Plateau Conditions
}

\author{
Meng Xia, Changlu Zhao, Fujun Zhang * and Ying Huang \\ School of Mechanical Engineering, Beijing Institute of Technology, Beijing 100081, China; \\ lecishibi@aliyun.com (M.X.); clzhao@bit.edu.cn (C.Z.); hy111@bit.edu.cn (Y.H.) \\ * Correspondence: zfj123@bit.edu.cn; Tel.: +86-139-1125-4765 \\ Academic Editor: Wenming Yang \\ Received: 24 March 2017; Accepted: 8 May 2017; Published: 17 May 2017
}

\begin{abstract}
In order to improve the diesel engine performance under plateau (high altitude) conditions, a new Speed Adjustable Compound (SAC) supercharging method is proposed. A simulation model based on a six-cylinder V-type turbocharged intercooler diesel engine is built on the GT-POWER platform, and then simulation-based research is carried out. A genetic algorithm (GA) is used to identify the best operation parameters, including the supercharger speed and fuel injection quantity under steady state conditions. Transient performance is obtained through starting process simulation of a vehicle with SAC engine on the MATLAB/Simulink GT-POWER co-simulation platform. Both the steady and transient performance of the SAC engine are compared with those of the original engine. Results show that the torque of the SAC engine at full load is significantly increased when the engine speed $n<1600 \mathrm{r} / \mathrm{min}$. The increment of the maximum torque can reach up to $31 \%$ at $1000 \mathrm{r} / \mathrm{min}$ compared to that of the original engine, while the peak torque is increased by $9 \%$. The fuel consumption deterioration is restricted within $5 \%$. What's more, the SAC engine can help reducing the acceleration time by $20 \%$ during tip-in pedal events during the vehicle starting process.
\end{abstract}

Keywords: diesel engine; GT-POWER; genetic algorithm; co-simulation; plateau conditions

\section{Introduction}

The air pressure and air density experience sharp declines at high elevation, which causes a large drop in the air intake flow of diesel engines [1,2]. Many aspects of the performance of the traditional turbocharged diesel engine are deteriorated as a result, such as power, fuel consumption and emissions $[3,4]$. The compressor may experience surge or over-speed problems. Besides, the turbo lag problem can't be ignored when engine exhaust energy is lacking [4].

In recent years, many supercharging technologies have been applied to improve the plateau performance of diesel engines. $\mathrm{Li}$ [5] applied a turbocharged system with waste gate in a CA6110/125Z1A2 diesel engine. The results showed this method could improve the torque performance during low engine speeds and avoid over-speed problems of the compressor at high engine speeds, but it had poor full load torque at high engine speeds and bad economic performance because part of the exhaust gas was released at high engine speeds. Zhang [6] did some simulation research on a M11-C300 turbocharged diesel engine with a Variable Geometry Turbocharger (VGT). According to the simulation results, the VGT had high efficiency and could effectively solve the problem of turbo lag, but the increase of engine power at high altitudes was insufficient due to the compression ratio limitations. Liu et al. [7] did some research on a $6 \mathrm{~V}$ diesel engine with two stage turbocharged systems and found that at $4500 \mathrm{~m}$ altitude, this charging system could improve the 
engine power to $85 \%$ of its level at sea level, but the problem of turbo lag still existed in the two stage turbocharged system.

Electric supercharging has the advantages of fast acceleration and can provide very high spontaneous boost pressure while the car is pulling away at low revolutions. This was demonstrated by Audi in the Audi RS 5 TDI concept [8].

Mechanical compound supercharging was previously explored by various groups [9-11] and firstly applied by Volkswagen to improve the torque performance of gasoline engines. A $1.4 \mathrm{~L}$ Twin-charger Stratified Injection (TSI) engine could have the same output power as a $2.31 \mathrm{~L}$ Natural Aspiration (NA) engine, but the fuel consumption was increased [12]. The system structure adopted a roots-type supercharger and a turbocharger in series. The transient characteristics of the engine were improved by the supercharger, and the pressure ratio was improved by the compound charging system.

Because the transmission ratio between the supercharger and engine are fixed, it is impossible to optimize the engine intake performance according to the working characteristics, which may lead to higher fuel consumption. In addition, the air flow rate and compression ratio of the roots-type supercharger are directly related to size and weight. The engine will demand high flow rates and compression ratios at high altitudes. This means much more size and weight increment for the roots-type supercharger [12]. Compared to the roots-type supercharger, the centrifugal supercharger is much smaller and more efficient. Related studies have shown that the intake pressure of a centrifugal supercharger driven by a motor can be optimized throughout the whole engine operation range $[13,14]$. In this study, the SAC system is introduced to solve the problems of turbo-lag and enhance the engine performance at plateau. The SAC system only needs to install a supercharger in front of the single stage turbocharged diesel engine.

In this paper, our research on modeling and simulation of the Speed Adjustable Compound supercharging diesel engine working at plateau is presented. The main features of the work are as follows: first, a simulation model of the SAC diesel engine is set up based on experimental data of an original turbocharged diesel engine. The influence of the supercharger speed is analyzed; Second, steady state operation parameters including supercharger speed and cycle fuel injection quantity of the SAC diesel engine are optimized to improve the engine performance at $4500 \mathrm{~m}$. Third, transient performance of the SAC engine is tested by simulating the vehicle starting process. The main purpose of this paper is to illustrate the significant advantages of the SAC system in improving power and transient performance of diesel engine at $4500 \mathrm{~m}$ altitude.

\section{System Modeling and Parametric Analysis}

\subsection{System Description}

The SAC system consists of one turbocharger and one supercharger. The turbocharger is always in operation, and the supercharger operates in the low and middle speed region of the engine. A bypass valve is arranged next to the supercharger.

When the supercharger is stopped, the bypass valve will open to maintain a normal air flow. To reduce the complexity of the system, only one intercooler is arranged in the rear of the compressor of turbocharger. A system schematic is shown in Figure 1. The supercharger has lower inertia and is driven by a motor, so it can accelerate fast and provide a high intake pressure during any situation lacking engine exhaust energy. The driving motor is connected to supercharger using the driving belt. The rotation speed of the driving motor can be adjusted from $0 \mathrm{r} / \mathrm{min}$ to $90,000 \mathrm{r} / \mathrm{min}$ continuously. Table 1 shows the main parameters of the supercharger drive system. 


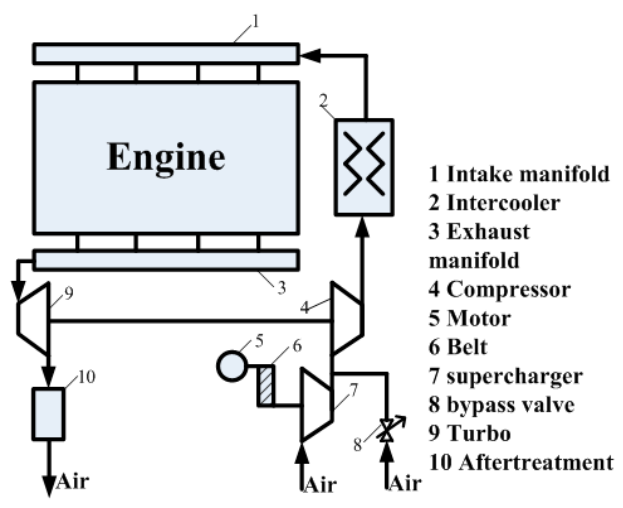

Figure 1. System schematic of SAC system.

Table 1. Parameters of the SC driven system.

\begin{tabular}{cc}
\hline Parameter & Value \\
\hline Belt driven ratio & 1.4 \\
Belt type & V-type \\
Motor speed & $0 \sim 6000 \mathrm{rpm}$ \\
Motor power & $20 \mathrm{Kw}$ \\
Drive ratio of SC & 7.5 \\
Max drive efficiency of SC & 0.97 \\
\hline
\end{tabular}

The turbocharger operates throughout the complete operational range. The original turbocharger is retained in this paper. One thing to note is that a compressor driven by an electric motor, namely a relatively low supercharging pressure and high current consumption, that's why influence of supercharger speed was analyzed below.

\subsection{System Model}

The analysis is based on a previously validated [15] GT-POWER engine model of a V-type six-cylinder turbocharged intercooled diesel engine, which employs a mechanical diesel pump and a turbocharger. The parameters of the engine are listed in Table 2.

Table 2. Engine parameters.

\begin{tabular}{cc}
\hline Parameter & Value \\
\hline Bore & $132 \mathrm{~mm}$ \\
Stroke & $145 \mathrm{~mm}$ \\
Compression ratio & $17: 1$ \\
Maximum torque & 1980 N.m@1300 r/min \\
$p_{\max }$ & $160 \mathrm{bar}$ \\
Maximum of $\mathrm{T}_{\mathrm{ex}}$ & $1023 \mathrm{~K}$ \\
\hline
\end{tabular}

The combustion process is described using a zero dimension (0-D) Predictive combustion model based on neural network (NN) and three Wiebe functions. This combustion model was proposed by Galindo et al. [16], and Serrano et al. [17,18]. Five operation factors-the outlet air temperature of the intercooler, the outlet air pressure of the intercooler, the fuel injection quantity, the injection timing and engine speed-which are related to the combustion process were chosen as the input parameters of the NN. The NN training data is obtained from experiments in a plateau environment simulation cabin covering the engine speed range from $1000 \mathrm{r} / \mathrm{min}$ to $2100 \mathrm{r} / \mathrm{min}$, load range from $10 \%$ to $100 \%, 17.5^{\circ}$ injection timing, $4500 \mathrm{~m}$ altitude, and intercooler temperature range from $40{ }^{\circ} \mathrm{C}$ to $90^{\circ} \mathrm{C}$. Nine parameters of the three Wiebe functions were chosen as the output parameters of the NN. 
The main procedures to establish the 0-D Predictable combustion model are explained in [19]: first, the rate of heat release was extracted through an analysis of the in-cylinder pressure experimental data. Second, the three Wiebe functions were used to describe the rate of heat release and the training data under different working conditions were obtained. Third, the RBF neural network was trained to build the relationship between the five operating parameters and nine three Wiebe function parameters.

The original engine model is built, and then the SAC engine is modeled by modifying the original model. One thing to note is that the engine power used in this paper is the net power $\left(P_{\text {net }}\right)$ which is obtained by deducting the power consumption of the supercharger from the engine power. The BSFC is calculated using this 'net power'.

\subsection{Influence of Supercharger Speed}

It is obvious that a higher supercharger speed $n_{s c}$ means a higher pressure ratio to the engine, thus $P_{\text {net }}$, the turbine inlet temperature $T_{e x}$, AFR and the peak pressure $p_{\max }$ of the engine will change accordingly. Results of numerical simulations at the operating point with $1500 \mathrm{r} / \mathrm{min}, 167 \mathrm{mg}$ per cycle in one cylinder and $4500 \mathrm{~m}$ altitude of the engine, and with $n_{s c}$ ranging from 44,200 r/min to 94,600 r/min are shown in Figures 2 and 3.

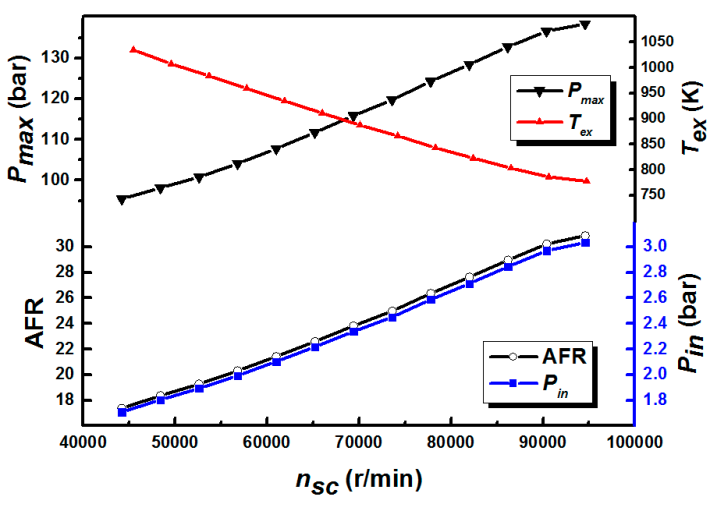

Figure 2. The influence of $n_{s c}$ to $p_{\max }, T_{e x}, \mathrm{AFR}$, and $p_{\text {in }}$.

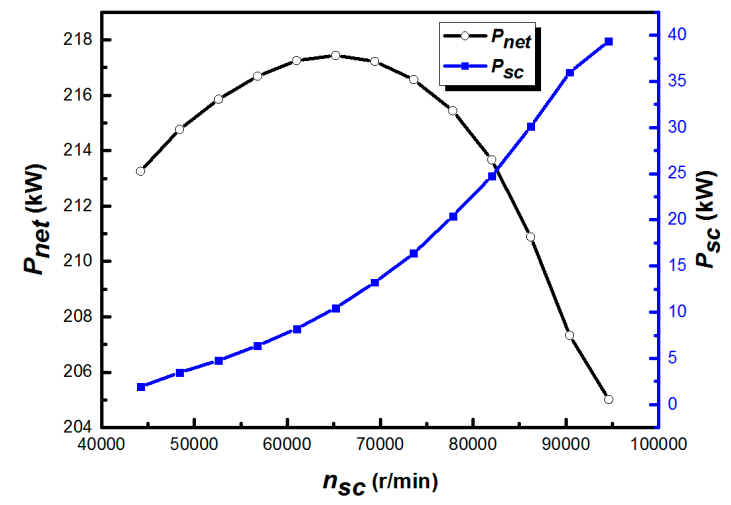

Figure 3. The influence of $n_{s c}$ to $P_{n e t}$ and $P_{s c}$.

With the increase of $n_{s c}, p_{i n}$ and $p_{\max }$ and AFR increase monotonously at the rate of $4.0 \times 10^{-5} \mathrm{bar} /(\mathrm{r} / \mathrm{min}), 7.3 \times 10^{-4} \mathrm{bar} /(\mathrm{r} / \mathrm{min})$ and $2.8 \times 10^{-4} 1 /(\mathrm{r} / \mathrm{min})$, respectively. Meantime $T_{e x}$ decreases at the rate of $4.410^{-3} \mathrm{~K} /(\mathrm{r} / \mathrm{min})$. In addition, the engine net power $P_{\text {net }}$ rises from $44,200 \mathrm{r} / \mathrm{min}$ to $67,000 \mathrm{r} / \mathrm{min}$ and then declines from $67,000 \mathrm{r} / \mathrm{min}$ to $94,600 \mathrm{r} / \mathrm{min}$. As $\mathrm{n}_{\mathrm{sc}}$ increases, $\mathrm{p}_{\text {in }}$ increases which can help to improve thermal efficiency; however, as can be seen from Figure 3, the power consumption of the supercharger will be high when $n_{s c}$ is too large, that's why the power decreases then. 


\section{Steady Optimization and Simulation}

\subsection{Optimization Aim}

Base on related reference and analysis in Section 2, the rotation speed of the supercharger and cycle fuel injection quantity are two main factors that affect the engine power and BSFC, so the next stage is to optimize these two factors, as well as to keep the engine at maximum effective output power and operating stably. The ranges for the two parameters are specified in Table 3.

Table 3. Input parameters for optimization.

\begin{tabular}{ccc}
\hline Parameter & Minimum & Maximum \\
\hline $\begin{array}{c}\text { Fuel injection quantity } \\
\text { (mg/cycle/cyl) }\end{array}$ & 20 & 220 \\
Supercharger speed (r/min) & 0 & 90,000 \\
\hline
\end{tabular}

\subsection{Performance Boundaries}

The following constraints should be considered and defined in advance in order to provide realistic and reasonable results:

1. Supercharger speed constraint: less than $90,000 \mathrm{r} / \mathrm{min}$.

2. Turbocharger speed constraint: less than $130,000 \mathrm{r} / \mathrm{min}$.

3. Maximum cylinder pressure: less than 162 bar.

4. Maximum turbine inlet temperature: less than $1023 \mathrm{~K}$.

5. Minimum AFR: more than 17.

\subsection{Optimized Algorithm}

The research problem in this section corresponds to a global non-linear optimization problem with multiple constraints. The genetic algorithm (GA) fulfills the role of global search particularly well, and is increasingly being applied. The design process of a GA mainly includes three aspects: selection, crossover and mutation. The selection process is regarded as the "natural selection law" in the genetic processes, expressing the optimization targets through the fitness function. A fitness function should be designed according to the feature of specific objects. An appropriate fitness function is critical to ensure the GA will run correctly and effectively [20].

\subsubsection{Fitness Function}

The static penalty functions are employed in this paper, and the magnitude of punishment depends on the violation degree. The violation degree $h$ is defined as follow:

$$
\begin{gathered}
h_{p}(\mathrm{x})=\frac{P_{\max }(\mathrm{x})}{162}-1 \\
h_{T}(\mathrm{x})=\frac{T(\mathrm{x})}{750}-1 \\
h_{n}(\mathrm{x})=\frac{n(\mathrm{x})}{130000}-1
\end{gathered}
$$

where $h$ is the assessment of the violation degree, subscripts of $h$ stand for violation object such as $p_{\max }$, $T_{e x}$ and $n(\mathrm{x})$. The vector $x[x 1, x 2]$ stands for optimization parameters. $x 1$ stands for the supercharger speed. $x 2$ stands for fuel injection quantity. The fitness function is expressed in Equation (4).

$$
\operatorname{FITNESS}(\mathrm{x})=P(\mathrm{x})-\sum K_{i} \times \max \left(h_{i}(\mathrm{x}), 0\right)
$$


where $P$ stands for the engine net power. $K$ represents the penalty parameters. If $p_{\max }$ or $T_{e x}$ or $n(\mathrm{x})$ exceeds the constraint, the penalty term in Equation (4) will work. A bigger fitness function value means the individual adapts the survival rules better. The genes of this individual are more likely to be used.

\subsubsection{Penalty Parameters $K$}

Penalty parameters $K$ described in Equation (4) have a great influence on the fitness function. The selection of $K$ has great effect on convergence of the optimization result. Zhu [21] has promoted a useful way to select $K$ which is called 'Fitness Equal to Zero at the Worst Point'. The main view is to restrict the elements of $x$ fairly and reduce the impact of $x$ value ranges. The biggest penalty should be imposed on operating points violating constraints most severely. That is to make the fitness function equal to zero. This way has been proved and is used in this paper.

Under a certain operating condition, the ranges of $x[x 1, x 2]$ are expressed as $x 1 \in[x 1 \mathrm{~min}, x 1 \mathrm{max}]$ and $x 2 \in[x 2 \min , x 2 \max ]$. The peak pressure $p_{\max }$ appears at the point $\mathrm{A}[x 1 \max , x 2 \max ]$, with the maximum supercharger speed and cycle fuel injection quantity. The maximum $T_{e x}$ and maximum $n_{t c}$ both appear at the point $\mathrm{B}[x 1 \mathrm{~min}, x 2 \mathrm{max}]$, with minimum supercharger speed and fuel injection quantity. The fitness function is set to zero at the points A and B. This is shown in Equations (5) and (6):

$$
\begin{aligned}
& \operatorname{FITNESS}(\mathrm{A})=0 \\
& \operatorname{FITNESS}(\mathrm{B})=0
\end{aligned}
$$

\subsubsection{Convergence Conditions}

Once the value of the fitness function and $x$ meet Equations (7) and (8) in 20 consecutive generations, the optimization results is considered convergent. The subscript $i$ ( $i=1,2$ in this paper) stands for the dimension of $x$, and subscript $j$ stands for the generation of the GA. The err stands for the error limits of convergence:

$$
\begin{gathered}
\left|\frac{\text { FITNESS }_{j}-\text { FITNESS }_{j-1}}{\text { FITNESS }_{j-1}}\right|<\text { err } \\
\left|\frac{x_{i, j}-x_{i, j-1}}{x_{i, j-1}}\right|<e r r
\end{gathered}
$$

\subsection{Optimization Realization}

To make it easier for optimization, the GT-POWER engine model is integrated into a co-simulation environment with MATLAB m-file, and the corresponding system block diagram can be seen in Figure 4. Simulation parameters are transmitted from MATLAB to GT-POWER, and then the engine numerical model is run. When the GT-POWER simulation is finished, GT-POWER will transmit the results such as $P_{n e t}, p_{\max }, T_{e x}$ and $n_{t c}$ back to MATLAB. Using these simulation results, Equations (1)-(8) are calculated to judge whether the optimization is converged, if not, the genetic processes will continue until it converged. GA input parameters are specified in Table 4.

Table 4. Parameters of GA.

\begin{tabular}{cc}
\hline Parameter & Value \\
\hline Population size & 20 \\
Crossover proportion & 0.98 \\
Mutation rate & 0.01 \\
Error limit (e) & 0.005 \\
\hline
\end{tabular}




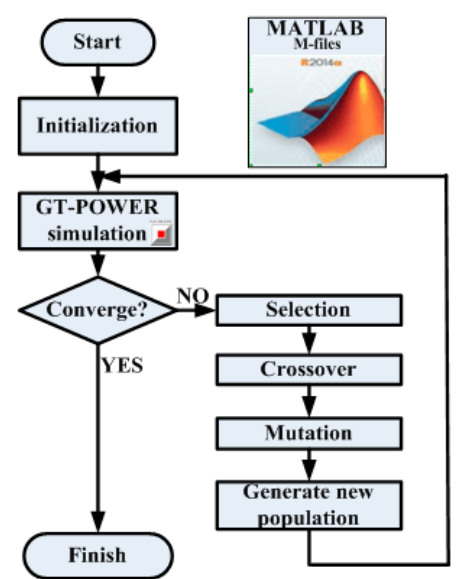

Figure 4. System block diagram.

\subsection{Simulation Results}

\subsubsection{Torque}

Figure 5a shows the torque output of the SAC engine at full load under various engine speeds. The torque has a certain improvement compared to the original engine when the engine speed $n<1600 \mathrm{r} / \mathrm{min}$. when the engine speed $n>1600 \mathrm{r} / \mathrm{min}$, the torque of the original engine is higher than that of SAC. That is why at the supercharger operation is stopped. The peak torque point is moved from $1400 \mathrm{r} / \mathrm{min}$ to $1300 \mathrm{r} / \mathrm{min}$ and has a significant increment of $9 \%$. What's more, the torque at $1000 \mathrm{r} / \mathrm{min}$ has increased by $31 \%$ compared to that of the original engine. However, the torque of SAC system is virtually identical with that of the original engine when $n>1600 \mathrm{r} / \mathrm{min}$. The reason is that the same turbocharger is used in these two schemes. Figure $5 a, b$ show that the torque and fuel injection quantity have the same varying tendency. The increment of air mass flow (Figure $5 c$ ) leads to much more fuel injection which helps to increase the torque and power. Figure $5 \mathrm{~d}$ shows the variation of $n_{s c}$.

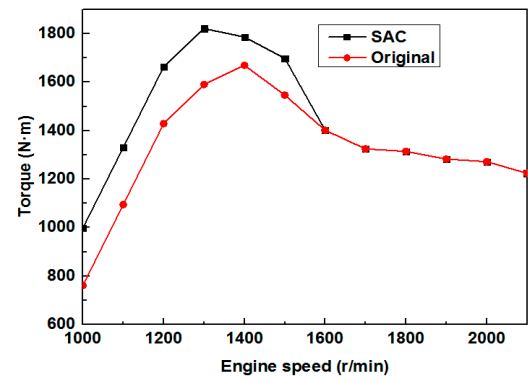

(a)

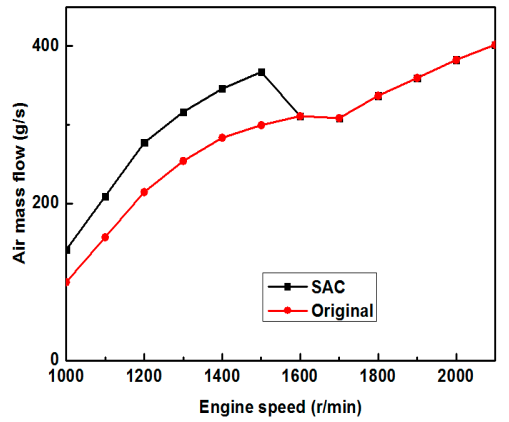

(c)

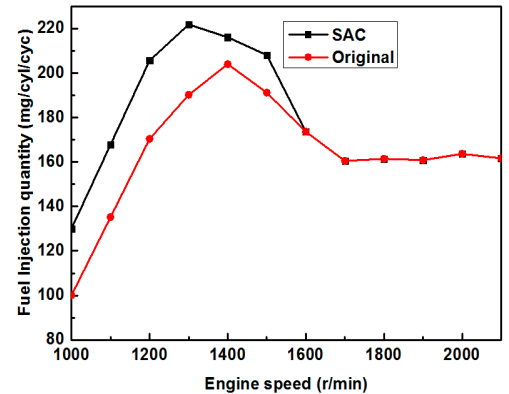

(b)

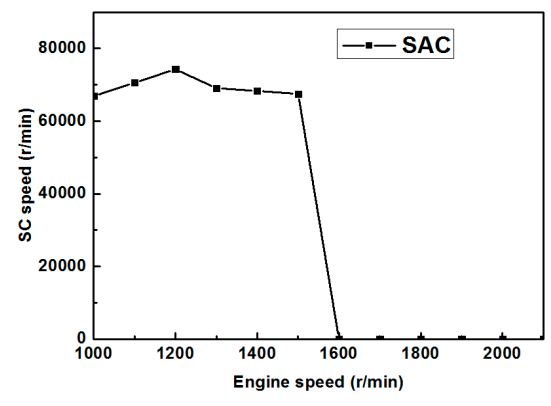

(d)

Figure 5. Full load optimization results: (a) Torque; (b) Fuel; (c) Air mass flow; (d) $n_{s c}$. 


\subsubsection{Fuel Consumption}

Figure 6 shows fuel consumption comparison between the SAC engine and original engine. The BSFC of the SAC engine is higher than that of the original engine when $1000 \mathrm{r} / \mathrm{min}<n<1300 \mathrm{r} / \mathrm{min}$ (the maximum increment is restricted within $5 \%$ ). This is because a significant amount of effective power is consumed by the supercharger. The phenomenon changes as the engine speeds up, due to the rise in efficiency both of the supercharger and turbocharger. This can be seen from Figure 7a,b, respectively.

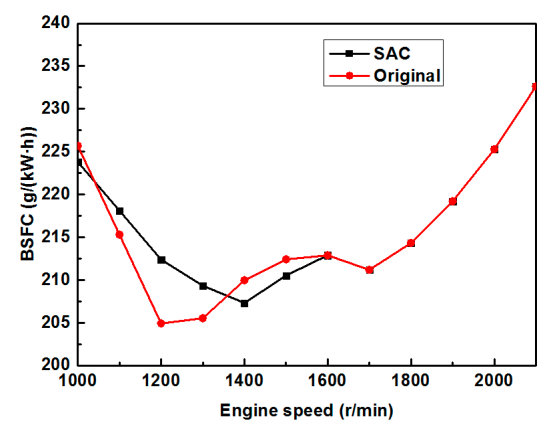

Figure 6. Full load optimization results: BSFC.

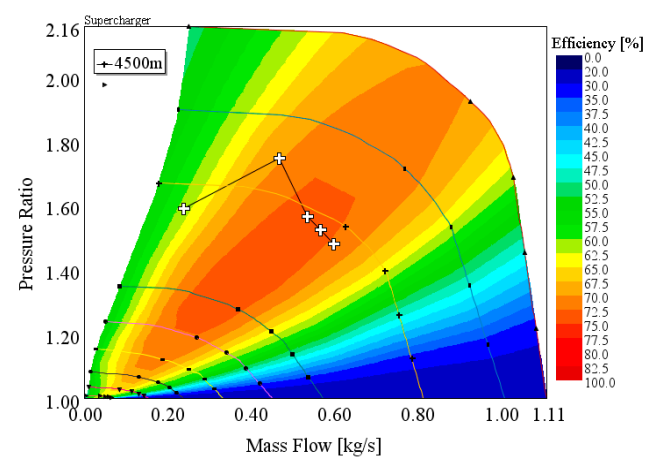

(a)

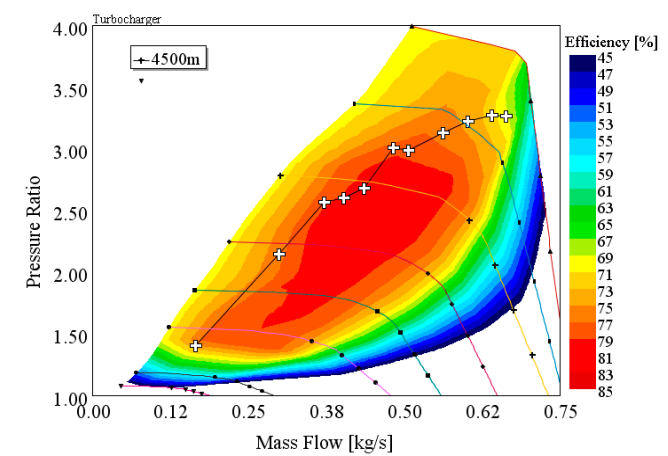

(b)

Figure 7. Full load optimization results. (a) Supercharger; (b) Turbocharger.

\subsubsection{Turbine Inlet Temperature}

In the plateau environment, the air mass flow decreases leads to an increase of the turbine inlet temperature $T_{e x} . T_{e x}$ is one of the important effects that limit the increasing of fuel injection at plateau [21]. Figure 8 shows that $T_{e x}$ rises with engine speeds up at full load conditions, except $1300 \mathrm{r} / \mathrm{min}$.

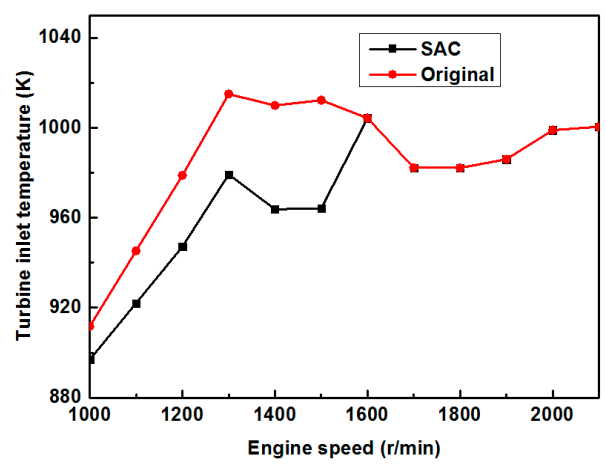

Figure 8. Full load optimization results. Turbine inlet temperature $T_{e x}$. 
This is mainly because that fuel injection quantity is increased as the engine speeds up and the engine has the maximum fuel injection quantity and smallest AFR (21 as can be seen from Figure 9) at $1300 \mathrm{r} / \mathrm{min}$. The supercharger operation is stopped when the engine speed is larger than $1600 \mathrm{r} / \mathrm{min}$ and $T_{e x}$ falls with the decrease of fuel injection quantity.

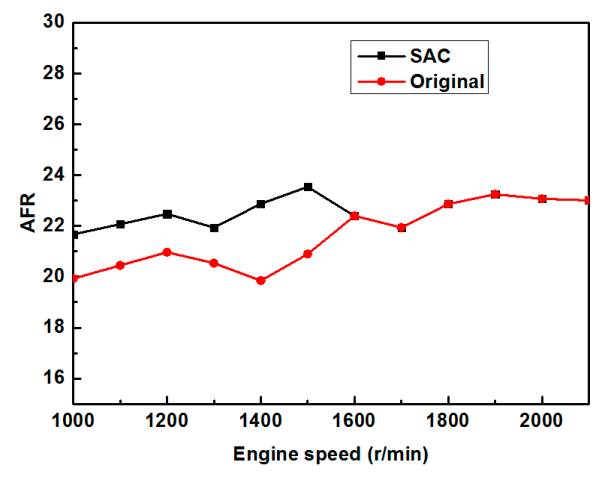

Figure 9. Full load optimization results. AFR.

\subsubsection{Rotate Speed MAP of the Supercharger}

The rotation speed MAP of the overall working conditions is shown in Figure 10. There is a very clear line which divides the overall area into 'STC mode' and 'SC mode'. The $n_{s c}$ increases with the increasing load under STC mode.

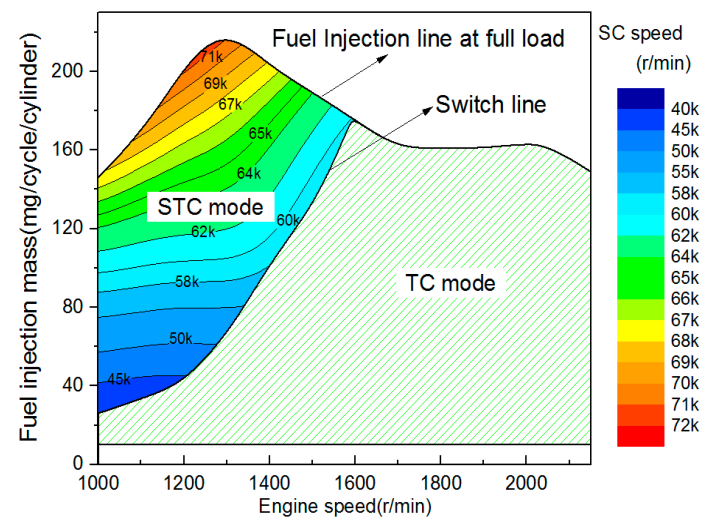

Figure 10. $n_{s c}$ of overall working conditions.

\section{Transient Simulation}

In this section, a vehicle model is built with this SAC diesel engine, and then a 'tip-in' simulation during the vehicle starting process is run to test the transient performance of the SAC engine.

\subsection{Simulation Setup}

Vehicle model is built on the GT-Power platform. Figure 11 shows the model architecture including the engine, the SAC system, ECU and equivalent moment of inertia of the vehicle $J^{\prime}$ and torque resistance from the wheel. Ignoring the elastic damping element of drive train, $J^{\prime}$ can be calculated using Equations (9)-(11) and expressed by Equation (12):

$$
\begin{gathered}
\frac{1}{2} m_{G} v^{2}=\frac{1}{2} J \omega^{2} \\
\frac{1}{2} \eta J_{1} \omega_{\text {in }}{ }^{2}=\frac{1}{2} J_{2} \omega_{\text {out }}{ }^{2}
\end{gathered}
$$




$$
\begin{gathered}
i=\frac{\omega_{\text {in }}}{\omega_{\text {out }}} \\
J^{\prime}=J_{e}+\frac{J_{t}}{\eta_{t} i_{t}{ }^{2}}+\frac{J_{f}+J_{W}+m_{G} r_{\text {tire }}{ }^{2}}{\eta_{f} i_{t}{ }^{2} i_{f}{ }^{2}}
\end{gathered}
$$

where $m_{G}$ is entire vehicle mass, $v$ is driving speed, $\omega$ is angular velocity, $J$ is moment of inertia of converted by vehicle quality, $J_{1}$ is moment of inertia of input shaft, $J_{2}$ is moment of inertia of output shaft, $\omega_{\text {in }}$ is angular velocity of input shaft, $\omega_{\text {out }}$ is angular velocity of output shaft, $\eta$ is transmissionefficiency, $J_{e}$ is moment of inertia of engine crankshaft, $J_{t}$ is moment of inertia of gearbox, $J_{f}$ is moment of inertia of main reducing gear, $J_{W}$ is moment of inertia of the wheels, $r_{\text {tire }}$ is radius of the tire, $i_{t}$ is transmission ratio of first gear, $i_{f}$ is transmission ratio of main reducing gear, $\eta_{t}$ is efficiency of gear box, and $\eta_{f}$ is efficiency of main reducing gear.

The relationship between resistance torque $T^{\prime}$ on the crankshaft and running resistance $\mathrm{F}$ can be expressed using Equation (13) where $\phi_{A}$ is proportion of engine accessory energy consumption. The specifications of the car are shown in Table 5 and $J^{\prime}$ is approximately $11 \mathrm{~kg} \cdot \mathrm{m}^{2}$.

$$
T^{\prime}=\frac{F r_{\text {tire }}}{i_{t} i_{f} \eta_{t} \eta_{f}\left(1-\phi_{A}\right)}
$$

Table 5. Vehicle Specifications.

\begin{tabular}{cc}
\hline Parameter & Value \\
\hline Car mass $(\mathrm{kg})$ & 16,000 \\
Wheel radius $(\mathrm{mm})$ & 300 \\
Rolling resistance coefficient & 0.05 \\
Power consumption ratio of accessory & 0.15 \\
First gear ratio & 2.68 \\
Main reducer's gear radio & 4.74 \\
Gearbox transmission efficiency & 0.92 \\
\hline
\end{tabular}

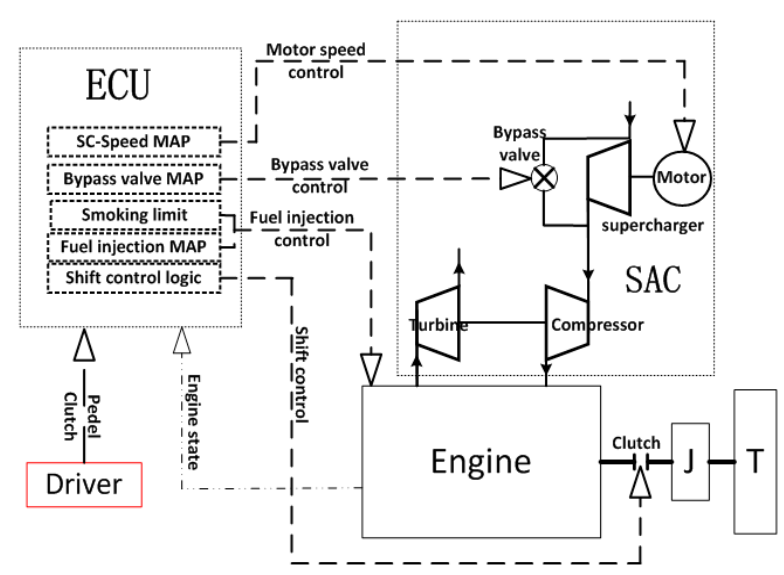

Figure 11. Vehicle simulation model.

\subsection{Simulation During the Vehicle Starting Process}

\subsubsection{Vehicle Starting Process Analysis}

Simulation results during the vehicle starting process are shown in Figures 12-15. The initial engine speed is $800 \mathrm{r} / \mathrm{min}$. The clutch engagement process is finished at $1.7 \mathrm{~s}$ and then the accelerator pedal is pushed from $0 \%$ to $100 \%$ within $0.8 \mathrm{~s}$. The engine speed decreases from $800 \mathrm{r} / \mathrm{min}$ to $500 \mathrm{r} / \mathrm{min}$ at $2.1 \mathrm{~s}$, after that the vehicle starts to speed up until it reaches steady-state. 
During the process, the SAC system enters STC mode at $2.7 \mathrm{~s}$ while the bypass valve is closed, and then the intake pressure starts to increase. The engine speed speeds up to $1600 \mathrm{r} / \mathrm{min}$ at $4.4 \mathrm{~s}$. After that, the SAC system begins switching from STC mode to TC mode. The switching process is finished at $5.4 \mathrm{~s}$. The mode-switch process is marked by an inlet reflux phenomenon which is caused by opening time of the bypass valve. This phenomenon will cause the decrease of intake air mass flow of the compressor which made it tend to surge, and this can be seen from Figure 15a.

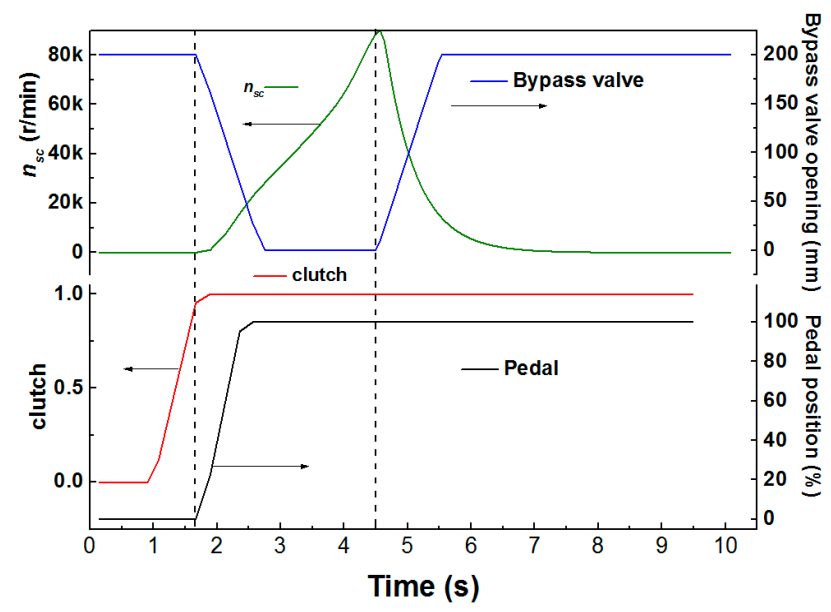

Figure 12. Vehicle starting process simulation results. $n_{s c}$, bypass valve, pedal, clutch.

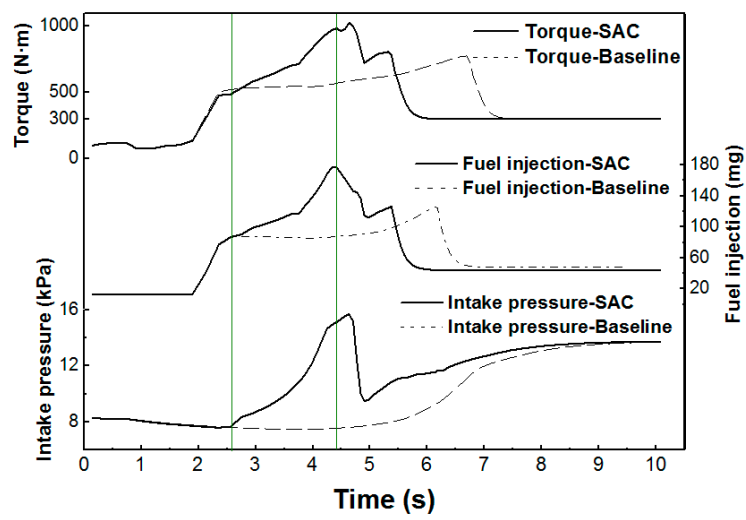

Figure 13. Vehicle starting process simulation results. Torque, Fuel injection and Intake pressure.

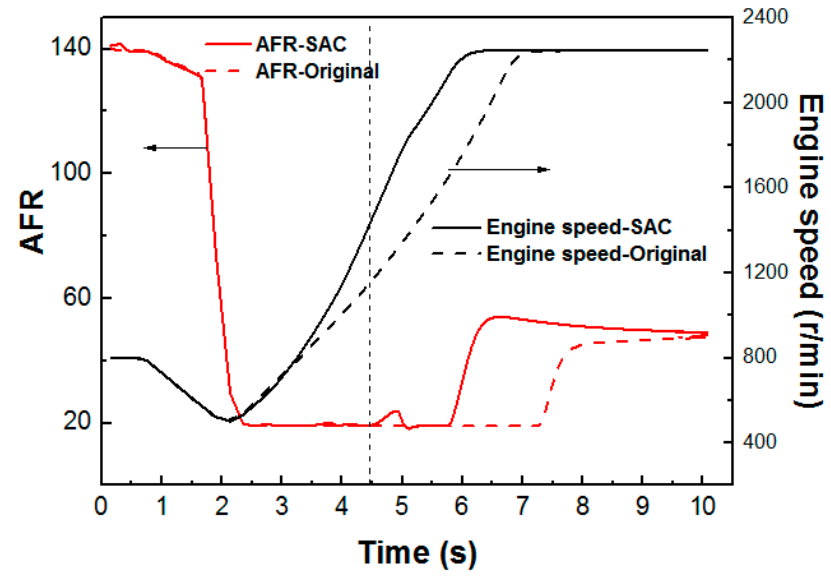

Figure 14. Vehicle starting process simulation results. Engine speed and AFR. 


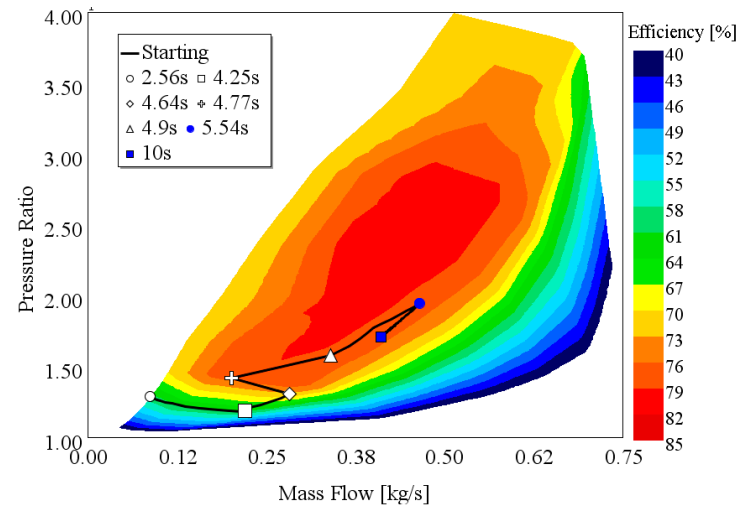

(a)

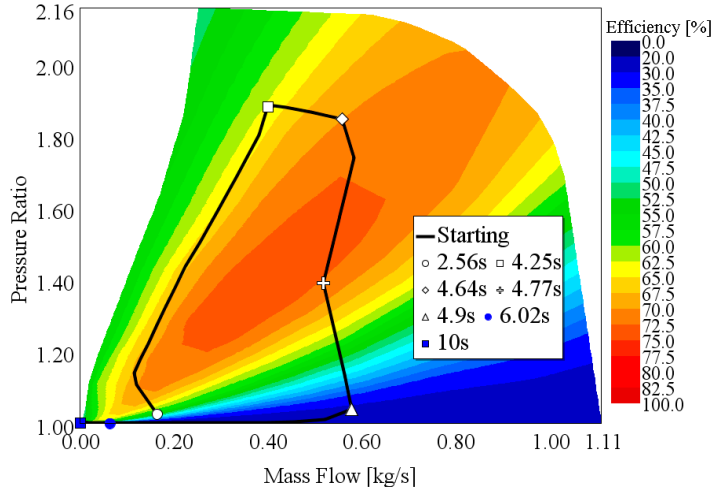

(b)

Figure 15. Vehicle starting process simulation results: (a) Compressor; (b) Supercharger.

\subsubsection{Comparison with Original Engine}

A similar vehicle model with an original engine is built and run to make a comparison. Comparison results are shown in Figures 13 and 14. The SAC engine speeds up faster than the original one and can reduce the acceleration time by $20 \%$. What's more, the SAC engine has much higher intake pressure which allows much more fuel to be injected into the cylinder (Figure 14). That is why the torque of the SAC engine is higher than that of the original engine.

\section{Conclusions}

In this paper, a Speed Adjustable Compound (SAC) supercharging system is proposed to improve performance of the diesel engine working under plateau conditions. The engine simulation model is built based on a zero dimension (0-D) predictable combustion model. The main results of this paper are summarized as follows:

(1) The SAC system is easy to implement and there is no need to change the original boosting system scheme. The speed of the supercharger can be adjusted according to the engine requirements, and high intake pressure is allowed in any situation lacking exhaust energy.

(2) A genetic algorithm (GA) is used to optimize the supercharger speed and fuel injection quantity to improve steady state performance of the engine at $4500 \mathrm{~m}$.

(3) Steady state performance of the SAC engine working at $4500 \mathrm{~m}$ has a significantly improvement compared to that of the original engine when the engine speed $n<1600 \mathrm{r} / \mathrm{min}$, whereby the peak torque is increased by $9 \%$. The maximum increment of brake specific fuel consumption (BSFC) is no more than $5 \%$.

(4) Transient simulation shows that the SAC engine can help to reduce the acceleration time of the vehicle by $20 \%$ compared to that of the original engine. The SAC engine has better transient performance than a turbocharged diesel engine and has potential to improve the vehicle transient performance and drivability under plateau conditions.

Acknowledgments: The authors acknowledge the assistance of Xilong Zhang and Jie Yang for language. The research is supported by National Science Foundation of China (grant No. 51475043).

Author Contributions: M.X., F.Z. and C.Z. conceived and designed the experiments; M.X. performed the experiments; M.X. and F.Z. analyzed the data; C.Z. contributed reagents/materials/analysis tools; M.X. wrote the paper." All authors read and approved the manuscript.

Conflicts of Interest: All authors declare no conflict of interest. 


\section{Nomenclature}

$n_{s c} \quad$ Rotate speed of supercharger $[\mathrm{r} / \mathrm{min}]$

$p_{\text {in }} \quad$ Intake pressure [bar]

$P_{\text {net }} \quad$ Engine net power $[\mathrm{kW}]$

$P_{S C} \quad$ Power consumed by the supercharger [kW]

$n_{t c} \quad$ Rotate speed of turbocharger [r/min]

$T_{e x} \quad$ Turbine inlet temperature [K]

$p_{\text {max }} \quad$ Peak pressure [bar]

0-D Zero Dimension

SC Supercharging

GA Genetic Algorithm

NN Neutral Network

AFR Air Fuel Ratio

SAC Speed Adjustable Compound

BSFC Brake Specific Fuel Consumption

$n \quad$ Engine speed

TSI Twin-charger Stratified Injection

VGT Variable Geometry Turbocharger

NA Natural Aspiration

STC Supercharging and Turbocharging

\section{References}

1. Liang, L.G.; Jiang, D.M. Some predictions of turbocharged high speed diesel engine performance at high land. Trans. CSICE 1983, 2, 1-18.

2. Liu, R.L.; Zhou, G.M.; Li, J.; Dong, S.R.; Ping, Z.; Fei, G.E. Calibration of common-rail diesel engine at high altitudes under full load operating conditions. J. Combust. Sci. Technol. 2012, 18, 199-205.

3. Zhu, Z.X.; Zhang, F.J.; Han, K.; Liu, Y.Y.; Luo, G.L.; Yun-Long, L.I. Adaption of fuel injection parameters for turbocharged diesel engines working at high altitude. Acta Armamentarii 2014, 35, 583-589.

4. Galindo, J.; Climent, H.; Guardiola, C.; Doménech, J. Strategies for improving the mode transition in a sequential parallel turbocharged automotive diesel engine. Int. J. Automot. Technol. 2009, 10, 141-149. [CrossRef]

5. Li, W. Study on Adaptability of CA6110/125Z1A2 turbocharged diesel engine in Qing Zang Plateau. Automob. Technol. 2001, 7, 5-12.

6. Zhang, H.; Zhuge, W.; Zhang, Y.; Hu, L. Study of the control strategy of the plateau self-adapted turbocharging system for diesel engine. Sae International Powertrains, Fuels and Lubricants Congress, 2008, 2008-01-1636.

7. Liu, X.H.; Wei, M.S.; Ma, C.C.; Shi, X. Simulation on one-stage and two-stage turbocharged diesel engines at different altitudes. Trans. CSICE 2010, 28, 447-452.

8. Knirsch, D.I.S.; Weiss, D.I.U.; Zülch, D.I.S. Electric supercharging in the Audi RS 5 TDI concept. MTZ Worldw. 2015, 76, 14-19. [CrossRef]

9. Matsura, Y.; Nakazawa, N.; Kobayashi, Y.; Ogita, H.; Kawatani, T. Effects of various methods for improving vehicle startability and transient response of turbocharged diesel trucks. Int. Congr. Expos. 1992, 920044.

10. Schmitz, T.N.; Holloh, K.D.; Jurgens, R. Potential of additional mechanical supercharging for commercial vehicle engines. Ground Veh. Sect. 1994, 942268.

11. Han, K.; Zhu, Z.X.; Zhang, F.J.; Yun-Long, L.I.; Geng, F.U.; Zhang, Z.Y. Research on composite adjustable supercharged program of diesel engine for power recovery at plateau. Acta Armamentarii 2013, 34, $129-136$.

12. Rose, A.; Akehurst, S.; Brace, C.J. Modelling the performance of a continuously variable supercharger drive system. Proc. Inst. Mech. Eng. Part D. J. Automob. Eng. 2011, 225, 1399-1414. [CrossRef]

13. Bhinder, F.S. Supercharging compressors-problems and potential of the various alternatives. SAE Int. Congr. Expos. 1984, 840243.

14. George, S.; Morris, G.; Dixon, J.; Pearce, D.; Heslop, G. Optimal boost control for an electrical supercharging application. SAE Tech. Pap. 2004, 2004-01-0523. 
15. Zhu, Z.X.; Zhang, F.J.; Li, C.J.; Han, K. Calibration for fuel injection parameters of the diesel engine working at plateau via simulating. Adv. Mech. Eng. 2014, 1, 1-8. [CrossRef]

16. Galindo, J.; Luján, J.M.; Serrano, J.R.; Hernández, L. Combustion simulation of turbocharger HSDI diesel engines during transient operation using neural networks. Appl. Therm. Eng. 2005, 25, 877-898. [CrossRef]

17. Serrano, J.R.; Arnau, F.J.; Dolz, V.; Piqueras, P. Methodology for characterization and simulation of turbocharged diesel engines combustion during transient operation, Part 1: Data acquisition and post-processing. Appl. Therm. Eng. 2009, 29, 142-149. [CrossRef]

18. Serrano, J.R.; Climent, H.; Guardiola, C.; Piqueras, P. Methodology for characterisation and simulation of turbocharged diesel engines combustion during transient operation, Part 2: Phenomenological combustion simulation. Appl. Therm. Eng. 2009, 29, 150-158. [CrossRef]

19. Zhu, Z.X.; Zhang, F.J.; Wu, T.T.; Han, K.; Liu, Y.Y.; Peng, Q. Zero-D predictable combustion model based on neural network and modeling. Trans. CSICE 2015, 33, 163-170.

20. Kalogirou, S.A. Artificial intelligence for the modeling and control of combustion processes: A review. Prog. Energy Combust. Sci. 2003, 29, 515-566. [CrossRef]

21. Zhu, Z.; Zhang, F.; Li, C.; Wu, T.; Han, K.; Lv, J. Genetic algorithm optimization applied to the fuel supply parameters of diesel engines working at plateau. Appl. Energy 2015, 157, 789-797. [CrossRef]

(C) 2017 by the authors. Licensee MDPI, Basel, Switzerland. This article is an open access article distributed under the terms and conditions of the Creative Commons Attribution (CC BY) license (http:/ / creativecommons.org/licenses/by/4.0/). 